\title{
Interactive comment on "Contribution of hydroxymethanesulfonate (HMS) to severe winter haze in the North China Plain" by Tao Ma et al.
}

\section{Tao Ma et al.}

mat14@mails.tsinghua.edu.cn

Received and published: 15 April 2020

The comment was uploaded in the form of a supplement:

https://www.atmos-chem-phys-discuss.net/acp-2020-113/acp-2020-113-AC1-

supplement.pdf

Interactive comment on Atmos. Chem. Phys. Discuss., https://doi.org/10.5194/acp-2020-113, 2020. 